\title{
Integrated pest management for forests and trees, a review of FAO's activities
}

\author{
by Gillian Allard ${ }^{1}$
}

\section{Background}

FAO, the Food and Agriculture Organization of United Nations, is an international, inter-governmental organization, one of the 18 Specialized Agencies of the UN. There are 176 members of FAO (175 Member Nations and one Member Organization).

FAO's mandate includes: the collection and analysis of data related to agriculture which incorporates the forestry sector (including aspects of forest protection); the provision of policy and technical advice, and the provision of a neutral forum for technical and policy discussion and exchange of information.

FAO's activities in forest protection, may fall under any or all of the fields described above. FAO aims to assist countries to safeguard the health and vitality of forest ecosystems from insects, diseases and other harmful biotic and abiotic agents and provides advice on preventive measures and integrated control of insect and disease outbreaks which minimises the risks of transboundary transfer.

Following UNCED, countries have paid increased attention to improving forest management taking into consideration the productive, protective and environmental functions of forests. Through a number of international processes countries have identified and agreed upon a number of criteria which define sustainable forest management, and have specified indicators through which trends in reaching determined goals can be measured and monitored. The maintenance of health and vitality of forest ecosystems has systematically been included among the specified criteria, including in the "Montreal Process," in which Canada participates. Corresponding indicators in the Montreal Process include "area and percentage of forest affected by processes or agents beyond the range of historic variation." These agents include insects, disease and competition by exotic species (FAO, 1997a).

Fire, insects and disease are components of natural ecosystems but may negatively affect attainment of the objectives such as tree growth and survival, wood quality, wildlife habitat, recreation, scenic value, provision of forage for domestic animals and cultural resources. Every part of a tree can provide host material for insects and diseases and trees of all ages from seedlings to mature trees may be subject to attack. Pest activity can significantly reduce yield and quality of both wood products and non-wood products (FAO, 1994a).

Movement of insects and diseases has been facilitated by increased long-range air travel and reduced travel time, international trade of agricultural and forest products, and the international exchange of plant material. Introduced pests can be extremely destructive and have had damaging effects in recent years in both the developed and developing world in both biological and economic terms. Recent examples include: the leucaena psyllid, Heteropsylla cubana, which has spread into

'Forestry Department, FAO, Rome, Italy.
Asia and the Pacific islands and is now in Africa; the cypress aphid Cinara cupressi, thought to have been introduced from northern Europe, and which is now established in eastern and southern Africa and which has had serious effect on an important plantation species, Cupressus lusitanica; and the European wood wasp, Sirex noctilio which has spread into Argentina, Unuguay and southern Brazil affecting principally Pinus taeda, is now present in South Africa and which poses a potential threat to the large Chilean plantations of Pinus radiata (FAO, 1997a). On a smaller scale is the recent discovery in USA in 1996 of the Asian longhorn beetle, Anaplophora glabripennis, attacking predominantly maples and other hardwoods (Haack et al. 1997).

\section{FAO and Forest Pest Management}

FAO's activities in pest management have concentrated on direct support to member countries in the development of integrated pest management strategies in forestry, in counteracting insect and disease attacks in natural forests and plantations.

At the request of member countries, FAO, in collaboration with the International Plant Genetics Resources Institute (IPGRI), has organized technical workshops aimed at describing insects and disease which can be transmitted by seeds. To date two forestry workshops have been held focused on eucalypts and pines; plans are being finalised for a third workshop which will deal with seed insects and diseases of acacias and woody legumes (FAO/IPGRI, 1996, FAO/IPGRI, in press).

The range of forest pest management problems for which FAO has provided assistance, range from rat and monkey control in Sao Tome (1986) to assistance in control of neem scale and determining the causes of neem decline in Niger (FAO, 1994b). Assistance ranges from emergency aid through FAO's Technical Cooperation Programme (TCP), to longer term, externally funded projects to supplement national response to the specified pest problem, and meetings such as Expert Consultations or pest management workshops.

Projects generally offer more than emergency assistance, helping countries to develop integrated pest management strategies to prevent further outbreaks. Frequently, pest management components are also included as an integral part of more comprehensive forestry programmes such as in the project: "Afforestation, Forestry research, Planning and Development in the Three North Regions of China" which included advice on the safe importation of logs; and pest management in seed orchards of poplars and pine species. Pest control in forest nurseries may be targeted, as in a recent project in Peru, or particular pests or ecosystems may form the focus of assistance as in the cases of the projects: "investigating the possibilities for the control of Ips calligraphus in the Philippines," "preliminary trials with pheromone from Thaumetopeas bonjeani in Algeria," and "assistance with control of mangrove dieback in Bangladesh."

The importance of supporting networks and furthering cooperation among countries in the management of forest pests of regional importance have been recognized, and assistance has been provided for the development of forest pest man- 
agement networks such as the "Forest and Disease Network, for Eastern and Southern Africa" (FAO, 1995b).

Examples of some recent project work are given below:

\section{Leucaena Psyllid in East Africa}

The Leucaena psyllid, Heteropsylla cubana, is, like leucaena itself, native to portions of Mexico and Central America. While the insect causes little damge in the natural range of Leucaena in Central America, it has caused widespread damage in countries in which the tree species has been introduced (FAO, 1994c). The psyllid was reported simultaneously on Leucaena in Tanzania and Kenya in 1992. FAO provided assistance for emergency support to the governments of these two countries. Recognising the potential for rapid transboundary spread across the African continent, the project involved specialists from other countries in which Leucaena was grown, in information networks and regional workshops (FAO, 1995c).

Action included creation of awareness of the insect and its damage to favour early detection, training in surveys to monitor damage and seasonal population fluctuations of the insect and to estimate socio-economic impacts. Development and implementation of a regional strategy for managing this insect in eastern Africa using principles of IPM included design of a long term IPM programme with a strong training component. Importation of biological control agents resulted in their establishment in both Kenya and Tanzania (FAO, 1997b).

\section{Assistance in the Control of Nun Moth, Lymantria monacha in Lithuania and Poland}

In 1994, outbreaks of Nun Moth and Pine Caterpillar were detected in pine forests in the Republic of Lithuania and emergency treatment using aerial application of biopesticides was requested by the Government to protect important forests. In 1995, FAO provided emergency assistance including technical backstopping, training and the purchase of three sets of rotary atomisers for installation on spray aircraft used to apply Bacillus thurinigensis supplied by the Danish Ministry of Environment and Energy which cooperated with FAO in project execution. 17,000 ha of forests were sprayed in 1995 and a total of 21,650 ha in 1995/96. Recommendations resulting from the FAO project included the development of a medium term forest management strategy including pest management to minimise risks of further outbreaks through ensuring a healthy ecosystem capable of withstanding attack. In 1997 USDA Forest Service sent a mission to follow up on the FAO project and to further assist in the development of a long term strategy for forest pest management (FAO, 1995d).

In 1994 there was a severe reinfestation of Nun Moth threatening up to 3 million ha of forests in northern and northwestern areas of Poland. FAO assistance was provided at the request of the government through an evaluation mission, and through assistance in contacting donors to support an emergency campaign. This resulted in a partnership of donors from the European Union, National Fund for Environmental Protection and Management, the General-Directorate of State Forests, the World Bank, Danish Environmental Protection Agency and the UK "Know-how Fund." In 1994, 600,000 ha of pine forest in the northern and north-western areas were sprayed with Bacillus thurinigensis and insect growth regulators, thus helping to prevent serious losses (FAO, 1994d).
Emergency Assistance for Control of Scale infestations on Neem Trees in Nigeria

Neem, Aziadracta indica, is an important introduced forestry and amenity tree in the northern states of Nigeria, widely used in the establishment of shelterbelts. Attacks by the Oriental Scale, Aonidiella orientalis, were first detected in eastern Nigeria in 1987. The insect subsequently spread throughout the northern region of Nigeria. Attempts by the national autorities to control the spread were unsuccessful, and FAO emergency assistance was requested in 1994. FAO assisted in the production of an operations manual for surveys of neem scale attack, including advice on how to measure the impact of the scale on neem tree populations. Recommendations were made on the effective management of the pest including biological control options. A guide to the identification of diseases and pests of neem was also published (FAO, 1995a).

\section{Emergency Assistance to Control Wilt Disease Infestation on Takamaka in the Republic of the Seychelles}

Recent dieback and death of an important naturalised tree species of the Seychelles, Takamaka, Calophyllum inophyllum var takamaka, has caused considerable economic and environmental concern. The Takamaka tree, Calophyllum inophyllum L. var takamaka, is a dominant woodland species that grows along the beach crests of most of the islands of the Republic of the Seychelles. The species has long been an important timber tree for boat building and for construction and is now a significant amenity coastal tree for tourism and ecotourism, and it is the favoured habitat of many endangered species.

At the request of the government, FAO provided emergency assistance to help determine the causal agent and mode of transmission of this vascular wilt disease, to recommend immediate and long term strategies for control, to design surveys to determine distribution, range and severity of damage, to draw up monitoring procedures and to train national counterparts in control measures and monitoring (FAO, 1997c).

\section{Emergency Assistance for the Control of Siberian Pine Caterpillar in DPR Korea}

An outbreak of Siberian caterpillar, Dendrolinus sibiricus, in the Democratic Peoples Republic of Korea was first reported early in 1996 and by August 1996, 12350 ha or $1.8 \%$ of the forest area used for timber production had been infested. Of this, an estimated 4500 ha or $0.7 \%$ was classed as seriously damaged, implying more than $50 \%$ trees dead or dying. Based on previous experiences of outbreaks of the caterpillar in Poland, Russia and China, the outbreak would probably last for several years and with repeated defoliation and secondary infestations it would cause serious reduction of timber production as well as significant losses of seed (used for food and oil) and resin.

Following a request, FAO has been assisting DPR Korea initially with an evaluation mission in 1996, followed by an emergency aerial spraying operation using Bacillus thuringensis formulations (Bt var. kurstaki) of the most seriously affected forests in Ryanggang Province. Spraying was timed to coincide with spring emergence of the insect. Spray operations were followed by a monitoring and assessment to evaluate the effects of the treatment (FAO, 1997d). 


\section{Emergency Measures for Control of Gypsy Moth in Bulgarian Forests}

A severe outbreak of Gypsy Moth, Lymantria dispar, affecting oak forest and neighbouring fruit orchards, was reported in Bulgaria in 1996, when more than 10,000 ha of oak forest had to be treated. FAO was requested to provide assistance in 1997 by the Government through a project which is still ongoing (1998). To date, FAO has provided appropriate spray equipment, biopesticides and training in collaboration with USDA Forest Service. FAO is assisting the Government to seek further bilateral support to provide additional biopesticides as 327,529 hectares of forest need to be treated in the near future to prevent further economic losses.

\section{Integrated Pest Management, Forestry and Future Prospects}

Whilst $\mathrm{FAO}$, on request, can assist countries in meeting pest outbreak emergencies, ensuring that action is paralleled by adequate environmental measures, in the long term, FAO is helping countries to promote the sound management of forests which includes measures to protect forests from fire, insects and disease. Good management is the key to a healthy forest, and a healthy forest is a sign of sound forest management practices.

The concept of Integrated Pest Management (IPM) in forestry is still evolving. Too often pest outbreaks are treated as a crisis situation and often action is taken too late to prevent major damage to the resources. Future action to promote IPM in forestry could use the systems developed in agriculture as a model.

For over 30 years, FAO has promoted IPM in agricultural crops with a focus on helping to increase knowledge of farmers in the sound management of agroecosystems and on furthering improved decision-making to enhance pest control by natural processes, such as encouraging the occurrence of natural enemies of pests to reduce the dependence on pesticides.

IPM-FFS (Farmer Field Schools) were developed within the framework of the FAO Inter-Country Programme for the development and application of IPM in rice in South and SE Asia. As a training methodology it has worked well in Asia where 1.2 million farmers have now been trained to understand and implement IPM. The FFS approach is of growing importance in the current environment of decentralization of government services and in the light of widespread decline of funds available for extension services.

Field Schools have proven to be an effective approach for building upon farmer's knowledge of agroecosystems and assisting in better decision making on how to increase agricultural production through environmentally sound farming practices. Results from pilot IPM-FFS in smallholder vegetable/cash crop system in Kenya have shown that farmers can grow a healthy and profitable coffee, cabbage or tomato crop without any inorganic fertilizers and up to $50-70 \%$ reduction in pesticides, while sustaining or increasing yields by adopting appropriate organic and cultural approaches as well as non-chemical methods of pest control such as biocontrol, cultural methods such as mulching and use of biopesticides.

The IPM-FFS approach, which has been so successful in agriculture, could potentially be adapted for forest and tree management and an effective Field School approach developed for improved tree and forest health management. The demand for people-centred extension and technical support services will increase over the coming years with the decentralization of forest resource management. Local level (municipal, private owners, etc.) decisions will play an increasing role in forest management. Sustainable management of forests will be under-pinned by the capacity of individuals to determine best practices for increasing productivity.

\section{References}

FAO. 1994a. Ensuring Sustainability of Forest Through Protection from Fire, Insects and Disease. Cielsa, W.M. Readings in Sustainable Forest Management, FAO Forestry Paper 122. pp. 131-151.

FAO. 1994b. Operations Manual. Survey of Neem Decline in Niger. Guide to Methods and Procedures. October 1994 TCP/NER/4452. Based on the work of E.R. Boa and M.C. Racaut. 28 pp.

FAO. 1994c. Leucaena Psyllid in the Asia-Pacific Region: Implications for its Management in Africa. Based on the work of Banpot Napompeth. RAPA Publication 1994/13.27 pp.

FAO. 1994d. Assessment of the 1994 Outbreak of Nun Moth, Lymantria monacha, in Poland and Proposes pest management Activities FO 2/354. 23 pp.

FAO. 1995a. A Guide to the Identification of Diseases and Pests of Neem (Azadirachta indica) based on the work of E.R. Boa. RAP Publication: 1995/41. 71 pp.

FAO. 1995b. Formation of an African Forest Pest Management Network. By G.B. Allard, S.M. Murphy, W.M. Ciesla \& S.M. Mbagathi. In Proc. International Consultative Meeting of Forestry Directors and Policy-Makers, 24-28 April 1995, Muguga, Kenya. Rome. 82 pp. FAO. 1995c. Leucaena Psyllid; a Threat to Agroforestry in Africa. Dar es Salaam, United Republic of Tanzania, 10-14 October 1994. Workshop Proceedings. $237 \mathrm{pp}$.

FAO. 1995d. Assistance in Control of Nun Moth and Pine Caterpillar, Lithuania. Terminal Statement TCP/LIT/4554. 15 pp.

FAO. 1997a. State of the World's Forests $1997.200 \mathrm{pp}$.

FAO. 1997b. Introduction, Screening and Evaluation of Natural Enemies of the Leucaena Psyllid Heteropsylla cubana for Use in Biological control Programmes in Africa Final report TCP/RAF/4451. Based on the work of Day, R.K., B. T. Nyambo, G. Phiri, M.G. Hill, J.C. Nsengimana, K.E. Mutitu, S. T. Murphy. 32 pp.

FAO. 1997c. Emergency Assistance to Control Wilt Infestation on Takamaka in the Republic of the Seychelles. Final Report TCP/SEY/4552 pp.

FAO. 1997d. Outbreak of Siberian Caterpillar in Ryanggang Province. Monitoring and Assessment of Treatment Programme. Final Report TCP/DRK/6612. $15 \mathrm{pp}$.

FAO/IPGRI. 1996. Technical Guidelines for the Safe Movement of Germplasm No 17. Eucalyptus spp. Edited by W.M. Ciesla, M. Diekmann and C.A.J. Putter. 66 pp.

FAO/IPGRI (in press). Technical Guidelines for the Safe Movement of Germplasm. Pines. Haack, R.A., K.R. Law, V.C. Mastro, H.S. Ossenbrugen and B.J. Raimo 1997. New Yorks' Battle with the Asian Long-Horned Beetle. Journal of Forestry. pp. 11-15. 